\title{
INFORMATION SYSTEMS MANAGEMENT: AN AUSTRALIAN VIEW OF THE KEY ISSUES
}

\author{
Graham P. Pervan \\ School of Information Systems \\ Curtin University of Technology \\ GPO Box U1987, Perth 6001 \\ Email: pervan@bal.curtin.edu.au
}

\begin{abstract}
Studies investigating the key issues in IS management serve to better understand the concems of IS managers and help to guide IS researchers in choosing IS management problems worthy of investigation. This paper presents results from a study of the key issues facing the IS managers of Australia's largest 300 organisations which is part of a three-yearly longitudinal study. In order to gain consensus on the relative importance of the key issues, a three-round Delphi method was applied. The results reveal that IS strategic planning continues to be the paramount issue in our industry, as are many issues associated with IS strategic planning, including responsiveness of the IT infrastructure, effective use of the data resource, IS for competitive advantage, and a comprehensive information architecture. A greater emphasis on quality is also revealed in highly rated issues such as effective use of the data resource, data integrity and quality assurance, and the quality of software development.
\end{abstract}

\section{INTRODUCTION}

In the face of expanding information technology (IT) capabilities information systems (IS) professionals need a greater range of knowledge and skills. The current IT environment includes large mainframe computers, minicomputers, microcomputers, powerful workstations, servers and communications networks, local and wide, linking some or all of these together. This range of IT supports a variety of applications, development tools (such as CASE and 4GLs), expert systems, database systems and end-user tools which are growing in quantity, range and complexity.

The role of the IS manager has shifted from being the technical expert responsible for solving technical problems to a provider of information to support organisational objectives and goals. As such, the IS manager operates in the nexus between a changing IT environment and an organisational environment changing with mergers and takeovers, a recessionary economy, downsizing, outsourcing, total quality management and internationalisation.

This paper describes a recent study of the key information systems management issues facing the information systems managers of large Australian organisations. A detailed description of the research method (a three-round modified Delphi approach) is provided for information systems researchers with a particular interest in the research methods applied to this research area. The overall results of the study showing the relative importance of all issues considered is then presented and discussed. These results are then compared across sectors of Australian industry (government, service, manufacturing). A historical analysis is then discussed in terms of the changes indicated in this study relative to the only previous Australian study. Finally, the key results of the study are summarised and recommendations for future work are presented.

\section{STUDYING THE KEY IS MANAGEMENT ISSUES}

Identification of the information systems management issues which concem Australian IS managers in the current technological and economic environment is of value to researchers and practitioners alike. In 1988 such a study was undertaken and published in the Australian Computer Journal (Watson, 1989). This new study, undertaken in 1991, is a follow-up of the 1988 study and part of a longitudinal research project to study trends in the issues impacting upon Australian IS managers at approximately three-yearly intervals.

The key aims of this research project are to determine:

- Which IS management issues are expected to be the most important to Australian IS managers over the next three to five years and thus the most deserving of attention. 
- How much consensus exists about the relative importance of specific issues.

- Why some issues deserve more attention than others.

- What trends are emerging in the status of different issues over time.

- How the relative importance of these issues compares between Australian IS managers in different sectors (service, manufacturing, and government).

- Arising from the above, what aspects of IS management should then receive greater attention from Australian IS researchers.

- How the relative importance of these issues to Australian managers compares with their importance to their counterparts in the US and UK.

All of these aims, except the last, are discussed in this particular paper.

\section{THE RESEARCH METHOD}

In order to provide information concerning the key IS issues, a three-round Delphi study of the IS managers of the top 300 Australian organisations was conducted from June to November, 1991. The aim of the study was to identify and rank in order of importance the major issues facing Australian IS executives over the next 3 to 5 years. The approach taken was identical to the previous (1988) study and based on the methodology used by the MIS Research Center (MISRC) at the University of Minnesota where three previous key issue surveys have been conducted (Dickson et al, 1984; Brancheau and Wetherbe, 1987; Niederman et al, 1991).

Delphi, a group decision making process, is particularly useful for assessing the judgement of a large, dispersed group of experts (Bass, 1983). A typical Delphi study starts with an open-ended questionnaire that solicits opinions on the issue of the study. Succeeding rounds of the study feed back the previous round's results so that participants can revise their judgment. In theory, the Delphi process should continue until the group has reached consensus. In practice, however, the researcher frequently decides to end the process after two or three rounds, by which time firm trends have generally emerged.

In this particular study the open-ended questionnaire was replaced with the final set of issues from the 1988 study and additional issues which had come to light in the 1990 MISRC study (Niederman et al, 1991). The previous Australian study showed the same issues were of concern to IS managers in both Australia and the US, though not in exactly the same order. It was felt, therefore, that an update of the previous set of Australian issues with newer US issues would provide a fairly complete list of starting issues. This starting list is provided as Appendix 1 which shows all 34 initial issues and a one paragraph rationale for the issue provided to all participants so that all would have the same understanding of the issue.

\section{The Data Collection}

In the previous Australian study, modifications were made to the MISRC approach. First, participants were asked to rate each issue rather than identify and rank the top ten issues. Second, the Delphi method was modified to increase response rate. Because of the likelihood of a significant rate of attrition in a three-round postal survey, two modifications to the standard Delphi method were made. In round two, round one respondents were fed back their results, but round one non-respondents were also fed back the summary results. Also, the round three questionnaire was sent to anyone who had responded to either round one or round two. As these modifications kept the response rate stable (at about 25 percent) the same modifications were used in the 1992 study. The value of this approach was further borne out when the MISRC acknowledged its usefulness by modifying their own methodology in the same way (Niederman et al, 1991, p476). In our 1991 study these modifications helped to maintain the response rate at about 30 percent for each round (see Table 1).

\section{Round One}

The business magazine, Australian Business, provides an annual review of the top 500 Australian organisations. From the issue of December 5, 1990 (Parry, 1990), the top 500 (by revenue) was obtained and the largest 300 (on the basis of revenue) selected from these. This number was chosen as 
a compromise between increasing the sample size from the previous study (from 200 to 300 ) to improve response rate and cost and time constraints associated with larger samples. The list included publicly listed and private Australian companies, foreign-owned companies, and government authorities with headquarters across all states and overseas. The various current city telephone directories were used to obtain the address of the Australian head office of each organisation and each head office was telephoned to identify the name and title of their IS manager (or equivalent).

The 25 highest ranked issues of the third round of the 1988 Australian study formed the basis for the first round questionnaire and were augmented with nine new issues used in the 1990 MISRC study for a total of 34 round one issues. The issues were then randomly sorted to ensure the previous studies had no influence on the ratings for the 1991 study and a copy of the questionnaire was sent to each of the 300 IS managers. A full listing of the issues is shown in Appendix 1. Participants were asked "What do you consider to be the most critical issues facing IS executives over the next three to five years?" and were then-invited to rate each of the 34 issues on a 10-point scale where a 10 represented a highest priority issue and a 1 indicated a lowest priority issue. They were also offered the opportunity to change the wording of any issues or modify the rationale. Further, space was provided at the end of the form to write in additional issues and their rationale. After posting to the 300 in the sample, useable responses were received from 88 respondents (see Table 1), producing a response rate of 29.3 percent.

\section{Round Two}

After analysing the 88 responses from round one, all 300 of the original sample were sent feedback showing the results of this analysis. The round one analysis simply involved calculating the mean and standard deviation of the ratings for each issue and then sorting them in order of average importance from highest to lowest. These sorted lists were returned to the 300 participants and showed the individual issues and associated rationale (in order) with their average rating. All 34 round one issues were retained and the (few) additional issues were examined. There was no commonality among these additional suggestions and they involved issues which were already represented in other forms, so no others were added to the list of 34 . Round one respondents received their individual responses to each issue in addition to the average rating, whereas non-respondents to round one received only the averages. All 300 were again asked to rate the issues on the 10-point scale. In round two, useable responses were received from 97 participants (see Table 1), producing a response rate of 32.3 percent.

\section{Round Three}

The round two results were analysed in the same way as for round one. The mean and standard deviation were calculated and the issues were again sorted into order of importance from highest to lowest. The nine lowest average rating issues were deleted from the list and only the top 25 were retained for round three. In an attempt to explain a significant shift in importance (from 1988) for the issue "Specifying, recruiting, and developing human resources for IS", two additional issues were included which separated the recruitment element of the human resources issue from the development element. These 27 issues were sent to respondents and they were asked to rate the issues one last time. No non-respondents were included in round three and responses were solicited only from the 126 managers who had responded to either round one or round two (or both). Useable responses were received from 88 respondents (after two were discarded as part of the questionnaire was not returned), providing a response rate of 29.3 percent. The responses by round are shown in Table 1 below.

Table 1: Number of Responses

for Each Round
\begin{tabular}{|c|c|c|}
\hline Round 1 & Round 2 & Round 3 \\
\hline 52 & 52 & 52 \\
\hline 12 & - & 12 \\
\hline 7 & 7 & - \\
\hline- & 24 & 24 \\
\hline 17 & - & - \\
\hline- & 14 & - \\
\hline 88 & 97 & 88 \\
\hline
\end{tabular}




\section{Representativeness of the Sample}

The target population for this study was the top 300 Australian organisations from which 88 finally completed round three. While this represents a slightly higher response rate than the 1988 study (29.3 percent versus 24 percent) and the total number of responses is much higher (88 versus 48 ), the possibility always exists that the final group of respondents is not representative of the target population. In order to validate the representativeness of the participant sample its profile was compared with the target population in relation to both industry category (Alcohol and Tobacco, Automotive, Banking and Finance, etc.), type of organisation (Publicly Listed, Non-listed, Government, Foreign-owned, Other), and spread of organisations over the top 300 . A $\chi^{2}$ Goodness of Fit test was applied to the distributions in each case. This statistical test provides a measure of how closely a set of observed frequencies (the sample) fits the frequencies expected from a given probability distribution (the population).

The sample was found to be representative of the population on all three classifications. In the case of industry distribution the calculated $\chi^{2}$ was 12.4916 and for type of organisation the calculated $\chi^{2}$ was 6.0062 , both of which were not significantly different from zero at the $5 \%$ level of significance. In order to see that there was an even spread of organisations according to size (measured by the ranking according to gross revenue) the population was divided into six groups of 50 rankings (1-50, 51-100, $101-150,151-200,201-250,251-300$ ). The calculated $\chi^{2}$ was 5.125, also not significantly different from zero at the 5\% level of significance. In summary, all three tests on the sample indicate that it is representative of the top 300 Australian organisations.

\section{Consensus Achieved by the Delphi Method}

If a one shot sample had been used for this study, there would have been some danger of a large variation in opinion on the issue ratings and so the use of mean rating to place issues in order may have been subject to this uncertainty. Through the use of the Delphi Method it is argued that the multiple rounds and feedback leads to greater consensus among those surveyed. The average standard deviation (ASD) of the issue ratings in the three rounds was calculated. The Round One ASD was 2.08 , which decreased to 1.90 in Round Two, and finally 1.65 in Round Three. The decrease in variation in each round confirms that consensus did in fact improve with each round of the Delphi.

\section{THE RESULTS OF THE STUDY}

The average ratings in each round of the study for all issues in the final round are shown in Table 2 below. The issues eliminated after Round 2 because of their low importance rating were those relating to factory automation, data and document storage, office automation, relational DBMS, image technology, computer graphics, global systems, the asset value of information and software, and, lastly, artificial intelligence. With such a spread of issues there may be a number of reasons for their low importance, but almost all are more technical issues. It may be argued that their technical nature inherently makes them of less concern to IS managers, but the more likely explanation is that the IS managers are the best judges of what is needed for IS and they recognise that the organisational issues are more problematic in the long run for both the IS function and the organisation.

The issues appearing in the top ten make it clear that the organisational issues are indeed much more important to these IS managers. IS strategic planning is the top ranking issue. There is increasing pressure to do IS strategic planning (Henderson and Sifonis, 1988) despite the difficulties in doing it well (Lederer and Sethi, 1992). It can help to identify high return applications, provide better forecasts of requirements, find ways of improving the IS function, improve IS-user communication, increase top management support for IS and develop an organisation-wide information architecture (McLean and Soden, 1977). Many of the other highly ranked issues, therefore, such as a responsive IT infrastructure, aligning the IS organisation with the enterprise, effective use of the data resource, IS for competitive advantage, and a comprehensive information architecture, all arise from, or are promoted by, effective IS strategic planning.

In examining the link between the closeness of the IS manager (ISM) to the chief executive officer (CEO) of the organisation (measured by the number of intervening organisational levels) and the issue ratings, it was found that the strongest (positive) correlations were with IS strategic planning, 
competitive advantage, and information architecture. That is, these issues were more important where the ISM and CEO were further apart. The implication, therefore, may be that closeness of the ISM to the CEO leads to better control over these organisation-wide problems making them (literally) "less of an issue".

Table 2: Average Rating for All Issues by Round

\begin{tabular}{|l|c|l|l|}
\hline Issue & Round 1 & Round 2 & Round 3 \\
\hline IS Strategic Planning & 7.931 & 7.964 & 8.125 \\
\hline Responsive IT Infrastructure & 7.482 & 7.840 & 7.784 \\
\hline Aligning IS Organisation & 7.333 & 7.567 & 7.773 \\
\hline Effective Use of Data Res & 6.780 & 7.229 & 7.414 \\
\hline IS for Comp Advantage & 7.188 & 7.537 & 7.384 \\
\hline Information Architecture & 7.174 & 7.263 & 7.273 \\
\hline Data Integrity/Quality Ass & 7.024 & 7.052 & 7.126 \\
\hline Quality of Software Dev't & 7.082 & 7.211 & 7.115 \\
\hline Role/Contribution of IS & 6.705 & 6.939 & 6.909 \\
\hline Disaster Recovery & 6.902 & 6.688 & 6.837 \\
\hline End User Computing & 6.613 & 6.823 & 6.788 \\
\hline Org Learning/Use of IT & 6.964 & 6.800 & 6.779 \\
\hline EIS/DSS & 6.855 & 6.871 & 6.703 \\
\hline IS Effectiveness/Productivity & 6.635 & 6.813 & 6.674 \\
\hline Telecommunications & 6.159 & 6.386 & 6.565 \\
\hline Recr/Dev Human Resources & 6.566 & 6.220 & 6.235 \\
\hline EDI/MVI & 6.280 & 6.113 & 6.200 \\
\hline Info Security \& Control & 6.427 & 6.134 & 6.153 \\
\hline Integrating DP/OA/Comms & 6.500 & 6.160 & 6.023 \\
\hline Applications Portfolio & 6.095 & 6.033 & 5.965 \\
\hline IS Funding Levels & 5.964 & 5.853 & 5.965 \\
\hline Distributed Systems & 6.305 & 5.913 & 5.835 \\
\hline Integrating Packages & 6.119 & 6.140 & 5.814 \\
\hline CASE & 5.982 & 5.828 & 5.552 \\
\hline IS Influencing Org Structure & 5.805 & 5.408 & 5.337 \\
\hline Recruiting Human Resources & - & - & 5.294 \\
\hline Developing Human Resource & - & - & 6.518 \\
\hline
\end{tabular}

In examining the link between the closeness of the IS manager (ISM) to the chief executive officer (CEO) of the organisation (measured by the number of intervening organisational levels) and the issue ratings, it was found that the strongest (positive) correlations were with IS strategic planning, competitive advantage, and information architecture. That is, these issues were more important where the ISM and CEO were further apart. The implication, therefore, may be that closeness of the ISM to the CEO leads to better control over these organisation-wide problems making them (literally) "less of an issue".

Quality issues have gained greater pre-eminence in organisations, both in management and the development of systems. Approaches such as Total Quality Management (TQM) emphasise customer satisfaction and quality of service (Tobin, 1990). Assuring quality in systems development and data maintenance improves product quality and cost effectiveness (Humphreys, 1989). It is not surprising, therefore, that a number of quality issues appear in the top ten in this study, including "effective use of the data resource" (4th), "data integrity and quality and quality assurance" (7th), and "quality of software development" (8th).

One particular issue, "specifying, recruiting, and developing human resources for IS" was of particular interest. When this issue showed up as a fairly low-rated issue (compare its 1988 rating in Section 5) in the first two rounds, two additional issues were included in the final round to see of there was any significant difference between the recruitment and development aspects of this issue. The ratings 
shown at the bottom of Table 2 show that, as suspected, recruiting staff in the 90's economic environment of high unemployment was much less of an issue that developing the existing staff.

The issues of significance to the different sectors of Australian industry were then examined. In the final 88 respondents, 7 organisations were from the government sector (mainly airlines and state govemment insurance providers), 49 from the services sector, and 32 from the manufacturing sector. Table 3 below shows the issues appearing in the top ten in these sectors. The list of issues in the table is in the order of the top issues overall, and shows both the average rating for each issue in the given sector and the issue's rank in that sector.

Table 3: Top Ten Issues In Each Industry Sector

\begin{tabular}{|l|l|l|l|}
\hline Issue & Government & \multicolumn{1}{|c|}{ Service } & $\begin{array}{c}\text { Manufacturin } \\
\mathbf{g}\end{array}$ \\
\hline IS Strategic Planning & $7.714(5=)$ & $8.020(1)$ & $8.375(1)$ \\
\hline Responsive IT Infrastructure & $8.286(1)$ & $7.674(3)$ & $7.844(2)$ \\
\hline Aligning IS Organisation & $7.857(2=)$ & $7.834(2)$ & $7.656(3)$ \\
\hline Effective Use of Data Res & $7.857(2=)$ & $7.438(4)$ & $7.281(6)$ \\
\hline IS for Comp Advantage & $7.143(9=)$ & $7.388(5)$ & $7.433(5)$ \\
\hline Information Architecture & $7.714(5=)$ & $7.061(8)$ & $7.500(4)$ \\
\hline Data Integrity/Quality Ass & $6.571(14=)$ & $7.286(6)$ & $7.000(8)$ \\
\hline Quality of Software Dev't & $7.143(9=)$ & $7.163(7)$ & $7.032(7)$ \\
\hline Role/Contribution of IS & $7.857(2=)$ & $6.918(10)$ & $6.687(14)$ \\
\hline Disaster Recovery & $6.571(14=)$ & $6.937(9)$ & $6.742(11)$ \\
\hline & & & \\
\hline End User Computing & $7.143(9=)$ & $6.770(12)$ & $6.733(12)$ \\
\hline EIS/DSS & $6.423(18=)$ & $6.698(14)$ & $6.774(10)$ \\
\hline IS Effectiveness/Productivity & $7.429(7)$ & $6.708(13)$ & $6.452(16)$ \\
\hline Telecommunications & $5.714(23=)$ & $6.500(15)$ & $6.867(9)$ \\
\hline Dev Human Resources & $7.286(8)$ & $6.292(16)$ & $6.700(13)$ \\
\hline
\end{tabular}

The results in each sector are quite similar to the overall results, but not identical. Understandably, the service sector's top ten issues were the same as the overall top ten (since the service sector was the largest group in the total sample), though the order was slightly different. In the manufacturing sector, telecommunications squeezed into the top ten, indicating a greater reliance on this technology. Executive information systems and decision support systems also squeezed into the top ten in this sector, perhaps indicating a greater concern for productivity at the executive level. Disaster recovery rated highest in the services sector, indicating their reliance on critical systems and their sensitivity to down time (for example, in banking and finance).

Comments about the government sector should be taken carefully since the number (7) and the type in this group may make the sample unrepresentative of the government sector as a whole. However, it is interesting to note that data integrity and quality assurance rated much lower than in the other sectors. Further investigation must be made to determine whether this is due to the impact of the government software standard AS3563 and, if so, whether its low importance implies a job done well or a misplaced assumption that it is no longer a problem. On the other hand, IS effectiveness and productivity rated much higher than in the other sectors, possibly indicating the demand on this sector to perform in the face of political and community pressure. Finally, the high rating of the human resources development issue in the government sector may indicate some concerns in that sector with IS staff skills and their training programmes.

\section{AN HISTORICAL COMPARISON}

As discussed earlier, this research project closely followed the 1988 study (Watson, 1989), using the same methodology, tackling basically the same issues (with a few updates), and sampling from the same population (though the target population was increased from the top 200 to the top 300 Australian organisations by gross revenue). A direct comparison between the top ten issues in each 
study throws light on some changes over that time. Table 4 lists the top ten issues in each study and their comparative ratings and rankings.

Two new issues, responsive IT infrastructure and disaster recovery, were both found to be of great importance (ranked $2 \mathrm{nd}$ and 10th, respectively). It is perhaps comforting to see that the top ten issues from 1988, except for the human resources issue, all appeared in the top twelve in 1991, so there has not been a lot of change overall. There are quite significant changes, however, in their relative positions, with effective use of the data resource (6.61 and 9th to 7.414 and 4th) and data integrity and quality assurance (6.31 and 11th to 7.126 and 7 th) both rising significantly. These testify to the rising concem with quality and effectiveness throughout all organisational activities (not just IS). In addition, and perhaps as expected, IS strategic planning remains the top issue, since, as discussed above, it is central to the effective handling of so many of the other issues.

Table 4: Top Ten Issues - 1988 \& 1991

\begin{tabular}{|l|c|c|}
\hline Issue & 1991 & 1988 \\
\hline IS Strategic Planning & $8.125(1)$ & $8.09(1)$ \\
\hline Responsive IT Infrastructure & $7.784(2)$ & New Issue \\
\hline Aligning IS Organisation & $7.773(3)$ & $7.18(5)$ \\
\hline Effective Use of Data Res & $7.414(4)$ & $6.61(9)$ \\
\hline IS for Comp Advantage & $7.384(5)$ & $6.83(7)$ \\
\hline Information Architecture & $7.273(6)$ & $7.42(3)$ \\
\hline Data Integrity/Quality Ass & $7.126(7)$ & $6.31(11)$ \\
\hline Quality of Software Dev't & $7.115(8)$ & $7.20(4)$ \\
\hline Role/Contribution of IS & $6.909(9)$ & $6.98(6)$ \\
\hline Disaster Recovery & $6.837(10)$ & New Issue \\
\hline & & \\
\hline End User Computing & $6.788(11)$ & $6.74(8)$ \\
\hline Org'1 Learning/Use of IT & $6.779(12)$ & $6.38(10)$ \\
\hline Recr/Dev Human Resources & $6.235(16)$ & $7.61(2)$ \\
\hline
\end{tabular}

The most significant fall in importance is the specifying, recruiting and developing of human resources for IS, which has slipped from 7.61 (2nd) to 6.235 (16th). As previously discussed, the main reason for this decline is economic and this is borne out by the fact that the developing staff aspect of the issue is rated more important (at 6.518) than the recruiting aspect (at 5.294). When there is a tight job market with many applicants, it is understandable that IS managers have few concerns about attracting and retaining good staff.

\section{CONCLUSIONS AND FUTURE WORK}

This paper has presented some results from a study on the key issues facing the IS managers of Australia's largest 300 organisations and has concentrated on the current status and trends in these issues in Australia. It has made no comparisons with similar studies overseas. The data presented, however, has been more than rich enough to paint an interesting picture of these issues from a purely Australian point of view.

IS strategic planning continues to be the paramount issue in our industry, and the many other issues it impacts upon also rate highly in importance. These issues, which include the responsiveness of the IT infrastructure, effective use of the data resource, IS for competitive advantage, and a comprehensive information architecture, are all organisational and signify the growing need for IS people to look beyond the technical solutions to technical problems and to pay close attention to organisational requirements. Further, there is an increasing need for emphasis on quality and effectiveness in IS activities and for the organisation as a whole.

The analysis presented in this paper has, of course, some limitations. Firstly, no direct comparisons of the results have been made with recent overseas studies in the USA (Niederman et al, 1991) and in Europe (Doukidis et al, 1992). Secondly, the government sector element of this study is very small and may not be representative of the sector as a whole. A follow-up study is planned for the Commonwealth government (initially) to see how IS in our government sector compares with overseas 
experiences in the public sector (for example, Caudle et al, 1991). Finally, the historical evaluation possible from only two Australian studies (1988 and 1991) is obviously limited. However, the authors intend to continue using this research method to obtain snapshots on the key issues at about threeyearly intervals. In time, this longitudinal study will provide an interesting picture of the changing face of Australian IS management.

\section{ACKNOWLEDGMENTS}

I wish to thank Dr. Richard Watson of the University of Georgia for providing the research instrument and materials from his 1988 study and for providing advice on the execution of the Delphi. Further thanks are also due to the Westem Department of State Services and the Curtin Business School for joint funding of this project. Finally, I wish to acknowledge the useful comments provided by the anonymous reviewers of this paper.

\section{REFERENCES}

Bass, B.M. (1983) Organizational Decision Making. Homewood, Illinois: Irwin.

Brancheau, J.C. and Wetherbe, J.C. (1987) "Key Issues in Information Systems Management", MIS Quarterly, 11, 1, March, pp 23-45.

Caudle, S.L., Gorr, W.L. and Newcomer, K.E. (1991) "Key Information Systems Management Issues for the Public Sector", MIS Quarterly, 15, 2, June, pp 171-188.

Dickson, G.W., Letheiser, R.L., Wetherbe, J.C. and Nechis, M. (1984) "Key Information Systems Issues for the 1980's", MIS Quarterly, 8, 3, September, pp 135-148.

Doukidis, G.I., Smithson, S. and Naoum, G. (1992) "Information Systems Management in Greece: Issues and Perceptions", The Journal of Strategic Information Systems, 1, 2, March, pp 63-75.

Henderson, J.C. and Sifonis, J.G. (1988) "The Value of Strategic IS Planning: Understanding Consistency, Validity and IS Markets", MIS Quarterly, 12, 2, June, pp 187-200.

Humphrey, W.S. (1989) Managing the Software Process, Reading, Mass.: Addison-Wesley.

Lederer, A.L. and Sethi, V. (1992) "Root Causes of Strategic Information Systems Planning Implementation Problems", Journal of Management Information Systems, 9, 1, Summer, pp 25-45.

McLean, E.R. and Soden, J.V. (1977) Strategic Planning for MIS, New York: Wiley.

Niederman, F., Brancheau, J.C. and Wetherbe, J.C. (1991) "Information Systems Management Issues for the 1990's", MIS Quarterly, 15, 4, December, pp 474-500.

Parry, A. (1990) "The Top 500", Australian Business, December 5, pp 88-103.

Tobin, L.M. (1990) "The New Quality Landscape: Total Quality Management", Journal of Systems Management, 41,11, November, pp 10-14.

Watson, R.T. (1989) "Key Issues in Information Systems Management: An Australian Perspective1988", Australian Computer Journal, 21, 2, pp 118-129. 


\section{APPENDIX 1 \\ Key Information Systems Management Issues}

What do you consider to be the most critical issues facing IS executives over the next three to five years? Please indicate your views by rating each issue on the scale 1 to 10 , where 1 indicates a lowest priority issue and $\mathbf{1 0}$ indicates a highest priority issue. The more important the issue the higher the score. Use the space below to assign your ratings. Please feel free to change the wording of the issues or modify the rationale. Space is provided at the end of the form to write in additional issues.

Your rating

1.

2.

3.

4.

5.

6.

7.
Key issues and their rationale

Issue: Planning, implementing, and managing office automation.

Rationale: Office automation is being implemented by many organizations to improve "white collar" productivity. Problems arise in determining how this should be done and what the role of the IS should be.

Issue: Planning, implementing, and managing factory automation.

Rationale: Factories are being automated to establish an internationally competitive position. Many functions are involved -- manufacturing, engineering, research \& development, etc. Coordination of automation efforts is critical. What should the role of the IS department be? How should these new systems be integrated within themselves and within traditional IS applications?

Issue: Developing an information architecture.

Rationale: A corporate/global information architecture is needed to identify the major information categories used within an enterprise and their relationships to business processes. It is necessary to guide applications development and facilitate the sharing of data.

Issue: Improving information security and control.

Rationale: As organizations increase their dependence on information systems, there is a greater risk from destruction and alteration of data, disclosure to outside sources, and disruption of information services. Tight security controls and fault tolerant information delivery are becoming a necessity.

Issue: Improving IS strategic planning.

Rationale: It is increasingly critical to an organization's success that it align its long-range IS plan with its strategic business plan. Rapidly changing business environments, increased involvement of end-users, and accelerated technological change underscore the need to continue improving strategic planning skills.

Issue: Facilitating organizational learning and use of IS technologies.

Rationale: Organizations that prosper will be those that make use of appropriate new IS technologies in their entire operation. Business practices and organizational structures will need to be modified in many cases. IS also must demonstrate its own ability to leam and use new technology.

Issue: Specifying, recruiting, and developing human resources for IS. 
8.

9.

10

11.

12.

13.

14.
Rationale: Current and future shortages of qualified information systems personnel threaten the IS department's ability to keep up with the information needs of its parent organization. Career paths need to be clarified. More emphasis needs to be put on developing business skills.

Issue: Measuring IS effectiveness and productivity.

Rationale: The measurement of IS performance is crucial to its effective management. This is becoming more important as organizations invest more and more money in information systems.

Issue: Improving data integrity and quality assurance.

Rationale: Mainframe applications, timesharing extracts, and personal computer applications are all used to analyze data and prepare reports. Frequently there are discrepancies among these different data sources due to lack of controls in IS and user departments. Too often computer printouts are assumed to be accurate. Such assumptions can lead to faulty business decisions.

Issue: Improving the quality of software development.

Rationale: The application development backlog remains at unacceptably high levels. Users are getting impatient. Add to this the increasing costs of human resources and the need for improved effectiveness in systems development becomes clear.

Issue: Facilitating/managing executive and decision support systems.

Rationale: Increasing the ability to exploit situations for competitive advantage depends on enhancing the ability of management to "experiment" with decision possibilities. Many other issues also depend on this capability. Decision support tools have long been viewed as a method for introducing modelling tools to executives to improve their decision making, however those efforts have met with mixed success.

Issue: Selecting and integrating packaged application software.

Rationale: The changing relationship among costs of hardware, packaged software, and human resources makes managing this aspect of the business critical. Using purchased application software can cut costs, boost productivity, and increase user satisfaction, but it can result in poor integration of systems and serious maintenance problems.

Issue: Converting and using relational database management systems

Rationale: IBM once suggested that its major users convert to relational DBMS by 1990 . How? Is it really necessary for end-user applications? Can organizations afford the additional hardware and conversion costs? Too little is known about this technology.

Issue: Aligning the IS organization with that of the enterprise.

Rationale: The effectiveness with which IS can support the enterprise's information needs is dependent on the IS department's position within the enterprise. Too often IS is not located appropriately within the organization. 
15.

Issue: Promoting effective use of the data resource.

Rationale: The organization's data resource is growing in size, complexity, and value. Despite this, it remains largely unrecognized, inaccessible, and underutilized. IS must develop a climate within its department and throughout the organization which values the data resources as a corporate asset.

16.

Issue: Enabling electronic data interchange and multi-vendor integration.

Rationale: Electronic communications with vendors and customers may offer tremendous competitive advantage to a company. IS executives must push for basic industry standards. Standards would enable electronic data interchange and cost effective multi-vendor environments without major conversion costs or loss of functionality.

17.

Issue: Determining appropriate IS funding levels.

Rationale: There is no generally accepted way of establishing the level of IS funding relative to the other funding needs of the organization. This can put both IS and general managers at a disadvantage.

18.

Issue: Increasing understanding of the role and contribution of IS.

Rationale: IS is sometimes viewed as an overhead expense with little appreciation of its contributions to the organisation. This can lead executive management to make infeasible demands and to cut funding resulting in missed opportunities for the organisation.

19.

Issue: Integrating data processing, office automation, factory automation, and telecommunications.

Rationale: The capability now exists to integrate systems that are based on these diverse technologies. As organizations try to integrate their technologies, organizational and managerial problems will need to be solved.

20.

Issue: Managing data and document storage.

Rationale: Information stored in both electronic and hardcopy form is accumulating at a staggering pace. There is a need to provide for future data and document storage requirements.

21.

Issue: Planning and implementing a telecommunications system.

Rationale: Communication is the lifeblood of the organization. Using IS for competitive advantage often depends heavily on telecommunications. Rapid and major changes in the industry complicate this task.

22.

Issue: Managing the impact of artificial intelligence.

Rationale: Artificial intelligence may be the tool to integrate IS with other functions in the organization. Its potential is not well understood. Although it is becoming increasingly feasible, too little is known about managing this technology. 
23.

24.

25.

26.

27.

28.

29.
Issue: Using information systems for competitive advantage.

Rationale: In many businesses, long-term survival is dependent upon using information systems to gain competitive advantage. The business can be lost without it. Competitive advantage results from recognition of opportunities through creativity and innovation, followed by rapid implementation. These are historical weaknesses of IS.

Issue: Planning and management of the applications portfolio.

Rationale: The applications portfolio is rapidly increasing in size, complexity, and maintenance cost. Despite the longevity of the maintenance problem, too little is known about managing it effectively.

Issue: Making effective use of computer graphics.

Rationale: Computer graphics offer an effective way to present information. Problems need to be resolved in using graphics interactively and remotely, and integrating it with standard reporting mechanisms.

Issue: Facilitating and managing end-user computing.

Rationale: The proliferation of end-user computing through personal computers offers the promise of improved productivity but also the dangers of inadequate management control. Information systems management must balance control against the need for slack. Clarification of IS and end-user roles is a necessity.

Issue: Planning and using CASE technology.

Rationale: Significant progress has been made automating business functions within organisations; however, a vast productivity gain is possible if the automation process itself is automated. In principle, software systems can provide support for integrating the design efforts of project teams, for standardizing representation methods, and for generating code. While this technology is still being refined, providing support for systems development is extraordinarily complex and will require major changes within the IS function.

Issue: Developing and Managing Distributed Systems

Rationale: Distributed systems present a variety of challenges including: establishing and maintaining consistent data; physically connecting computers linked by various networks with seamless gateways; responding to increased demands for joint development projects with users; controlling wasteful duplication of efforts; and establishing guidelines for providing data resources to multiple versus local users.

Issue: Building a Responsive IT Infrastructure

Rationale: The combination of maintenance problems, evolving corporate architecture, package integration, user-developed systems and quality of the application portfolio will require extensive automation of the IT processes required to coordinate action and manage the business. Building an integrated technology platform is the key to enterprise and industry productivity. 
30.

Issue: Using IS to Influence Organizational Structure

Rationale: It is commonly accepted that new information technologies offer the potential to flatten organizational structure thereby creating a more responsive, flexible, and innovative firm. Information systems may also enable new dynamic organizational forms, further improving the firm's responsiveness to react to new opportunities.

31.

Issue: Establishing Effective Disaster Recovery Capabilities

Rationale: Down-side risks are increasing daily from the potential loss of business due to a disaster. Effective recovery plans must be in place and tested regularly to insure losses are minimized As organizational applications grow and become more integrated, the greater the risk becomes.

32.

Issue: Planning and Using Image Technology

Rationale: The utilization of image technology is growing in firms. There is an increasing need to integrate these into the IS arena and to consider their impact on technology planning and acquisition, hardware and software architecture, and user policies.

33.

Issue: Moving Toward Global Systems

Rationale: With increasingly global orientation of markets, suppliers, customers, etc. business will require global information planning, designs and implementations to permit effective and efficient operations. This will challenge current systems of data transfer, time concepts, cooperative work, and language utilization.

34.

Issue: Accounting for the Asset Value of Information and Software

Rationale: Currently, most internally developed software and information databases are expensed, not amortized. Effective long-term management requires an acceptable method of accounting for the asset value of software and databases. 